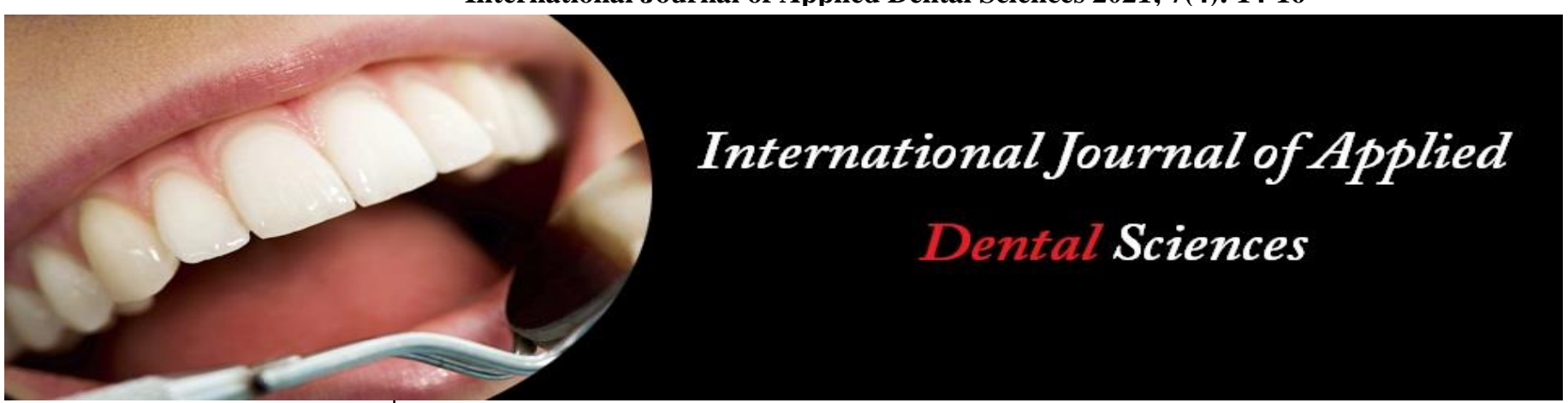

ISSN Print: 2394-7489

ISSN Online: 2394-7497

IJADS 2021; 7(4): 14-16

(C) 2021 IJADS

www.oraljournal.com

Received: 10-08-2021

Accepted: 12-09-2021

Dr. Jayaprasad Anekar

Professor and Head, KVG

Dental College and Hospital,

Sullia DK, Karnataka, India

Dr. Krishna Santhosh Kumar Assistant Professor, Amrita School of Dentistry (Amrita Vishwavidyapeetham) AIMS Health Care Campus Edappily, Kochi, Kerala, India

Dr. Jayalakshmi Baipadavu Senior Lecturer, KVG Dental College and Hospital, Sullia DK, Karnataka, India

Dr. Ivin Elsa John Former Post graduate student KVG Dental College and Hospital, Sullia DK, Karnataka, India

Corresponding Author: Dr. Krishna Santhosh Kumar Assistant Professor, Amrita School of Dentistry (Amrita Vishwavidyapeetham) AIMS Health Care Campus Edappily, Kochi, Kerala, India

\section{Accessory salivary tissue presenting as a mid-cheek mass: A case report}

\section{Dr. Jayaprasad Anekar, Dr. Krishna Santhosh Kumar, Dr. Jayalakshmi Baipadavu and Dr. Ivin Elsa John}

DOI: $\underline{\text { https://doi.org/10.22271/oral.2021.v7.i4a.1345 }}$

\section{Abstract}

Accessory parotid glands are salivary tissue collections seen as separate glandular mass detached from the main parotid gland lying on the masseter muscle. It develops from the branching of the blind end of the parotid tube and by glandular proliferation of secretory and stromal structures. They are anatomical variations seen in the mid cheek region with a frequency of $21 \%$ to $56 \%$ found in autopsy studies. The following case report depicts a case of accessory parotid gland presenting as a mid-cheek mass in the right buccal mucosa.

Keywords: accessory parotid gland, buccal mucosa, ultrasound

\section{Introduction}

Accessory parotid glands (APG) are ectopic salivary gland tissues. It is usually located near to the parotid gland approximately seven millimeters anterior to the main gland. Its size ranges within 0.5 to $1 \mathrm{~cm}$ and lies continuous with the masseter muscle along an imaginary line extending from the tragus of the ear to a midpoint between the ala of the nose and vermillion border of the lip ${ }^{[1]}$. This case reports describe a case of a patient presenting with a swelling in the right mid cheek region which was diagnosed as accessory salivary gland tissue.

Case report

A 40 year old female patient reported to the department of Oral Medicine and Radiology with the chief complaint of pain in the right cheek since 8 months which was gradual in onset, dull aching and intermittent in nature. Patient also reported of a swelling in the same region, which moves while touching that area. Pain is aggravated on pressing the area and gets relieved by its own after some time. She is under medication for diabetes mellitus and hypertension since 1 year. She reports of using betel quid without tobacco every day three to four times since 10 years. On extra oral examination a diffuse swelling of size $5 \mathrm{~cm} \times 4 \mathrm{~cm}$ was seen in the right parotid region extending from the tragus of the ear $3 \mathrm{~cm}$ anteriorly and inferiorly not extending beyond the lower border of the mandible (figure 1). On palpation it was non tender with soft to firm consistency, compressible and not reducible. On examination of buccal mucosa a nodule of size $1 \times 1 \mathrm{~cm}$ could be palpated which was roughly oval in shape, freely movable, slightly fibrous in consistency and tender. Salivary secretion of right parotid duct was considerably reduced on milking the gland. On hard tissue examination, generalized calculus and stains were found. Severe attrition of the teeth was also observed. She had retained deciduous teeth 53 and 63 and clinically missing 13 and 23.

A provisional diagnosis of right parotid sialadenitits with parotid lymphadenopathy was arrived after history taking and clinical examination. A clinical differential diagnosis of sialolithiasis, bacterial sialadenitis and sialadenitis due to other causes were considered due to similar clinical presentation. Patient was advised for soft tissue intraoral radiograph, anteroposterior view radiograph and salivary culture. No radio-opaque structures were identified in the radiographs and calcifications in the duct was ruled out (figure 2). Salivary culture was also negative. Panoramic radiograph was taken to rule out any abnormalities related to the dentition and supporting bone. 
Impaction of 13 and 23 with retained deciduous 53 and 63 was found on evaluation of the panoramic image (figure 3 ). Patient was advised for ultrasound of right cheek. It revealed a well-defined homogenously iso-echoic nodule in the right buccal space measuring $22 \times 8 \mathrm{~mm}$ anterior to the anterior border of right masseter muscle. There was no continuity of the nodular structure with the adjacent right parotid gland. No evidence of sialolithiasis was noted and a few enlarged right intraparotid lymphnodes were seen (figure 4). Ultrasonographic impression was given as accessory salivary tissue in the right buccal space.

Accessory parotid gland of the right side with secondary inflammation was given as the final diagnosis. Patient was reassured and advised not to keep manipulating that area often. Antibiotics and analgesics were prescribed and patient was reviewed after a week. She reported of significant reduction in pain. Later patient was recalled in intervals of one month and six months and patient remained completely asymptomatic.

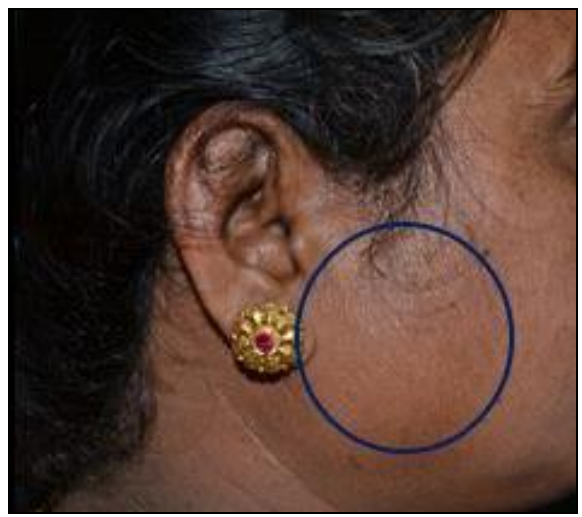

Fig 1: Extra oral view of the patient

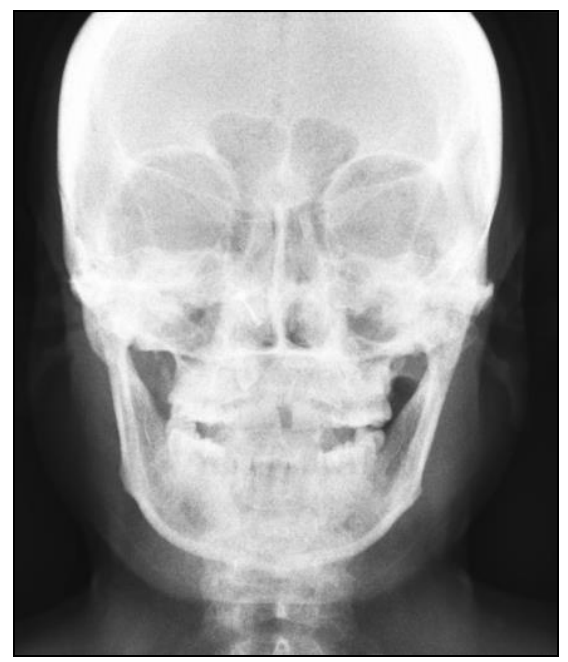

Fig 2: Antroposterior view

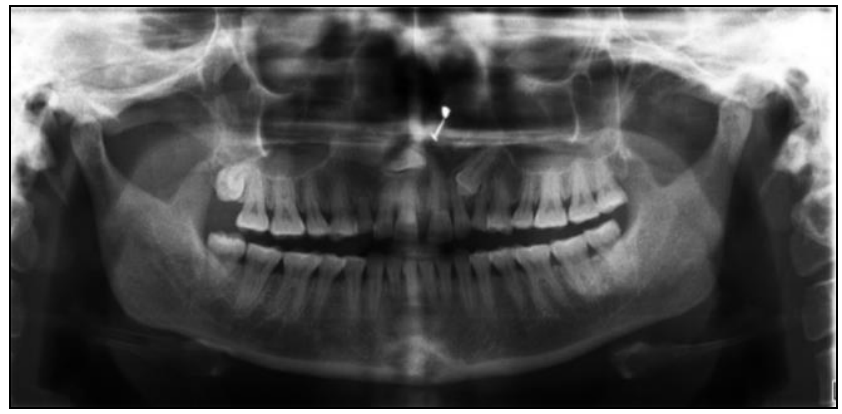

Fig 3: Panoramic radiograph

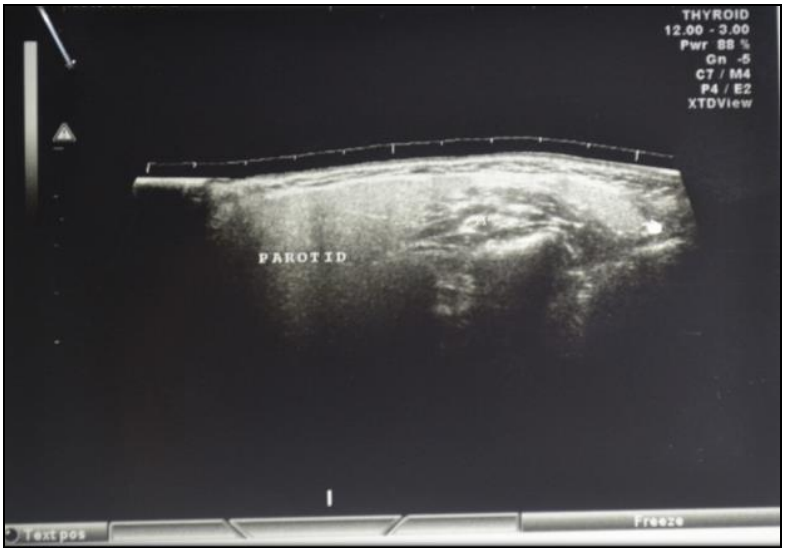

Fig 4: Ultrasonographic examination of right cheek

\section{Discussion}

During the development of the parotid gland three variations may be seen along its anterior border. No extension present anteriorly, extension present, but attached to the gland which is termed as facial process and a glandular mass, not attached to the main gland which is termed as accessory parotid gland. It appears as a flattened structure similar to a pea or a large lima bean as it is compressed between the masseter muscle and the skin ${ }^{[2,3]}$. It derives its blood supply from transverse facial artery and may have one or two ducts emptying into the Stensen's duct. APG and tumors arising from APG, arteriovenous malformations, lymph node enlargements, neural tumors or metastatic lesions should be considered for differential diagnosis during the evaluation of masses in the mid cheek area. Identification of an APG through routine radiographic examination is difficult hence ultrasonography can be used as the primary mode of assessment as done in the present case. Sialography can be carried out for detailed evaluation of ductal system and tributaries of the APG in detail ${ }^{[1,3]}$. Histopathologically APG's may be similar to the main parotid gland or may differ in its pattern of differentiation, containing both serous and mucous acini ${ }^{[4]}$. Accessory parotid gland tumors are rare accounting only 1 to $7.7 \%$ of all parotid gland tumors. Malignant transformation rate of tumors arising from APG's is 26 to $52 \%$ and hence have to be dealt with caution [1]. It is attributed due to the histologic pattern of the accessory glands and the lack of anatomic barriers which will result in accentuated soft tissue infiltration ${ }^{[5]}$

\section{Conclusion}

Accessory parotid gland is an anatomical variation seen as a separate salivary tissue from the main parotid gland. They may present as swellings in the mid cheek region and hence accessory parotid gland and its pathologies should be considered while evaluating mid cheek masses. Failure to do so can result in recurrence of neoplasms even after total parotidectomy or persistent sialadentitis.

\section{References}

1. Romano A, Faro LC, Iaconetta G, Committeri U, Audino $\mathrm{G}$, Salzano $\mathrm{G}$ et al. Oral and maxillofacial surgery cases 2020; 6: 100188.

2. Yadav GD, Yadav A, Soni J, Chaudhary G. Accessory parotid gland with ectopic fistulous duct - Surgical view: A case report and review of current literature. Natl J Maxillofac Surg 2014;5:236-9.

3. Frommer J. The human accessory parotid gland: Its incidence, nature, and significance. Oral Surg Oral Med 
Oral Pathol 1977;43:671-6.

4. Toh H, Kodama J, Fukuda J, Rittman B, Mackenzie I. Incidence and histology of human accessory parotid glands. Anat Rec 1993;236:586-90.

5. Ramachar SM, Huliyappa HA. Accessory parotid gland tumors. Ann Maxillofac Surg 2012;2(1):90-93. doi:10.4103/2231-0746.95334 